\title{
The impact of supply chain integration on performance: A contingency and configuration approach
}

\author{
Barbara B. Flynn ${ }^{\mathrm{a}}$, Baofeng Huo ${ }^{\mathrm{b}, \mathrm{c}, *, 1}$, Xiande Zhao ${ }^{\mathrm{d}, 2}$ \\ ${ }^{a}$ Kelley School of Business, Indiana University, 801 W. Michigan St., Indianapolis, IN 46202, United States \\ ' School of Management, Xi'an Jiaotong University, China

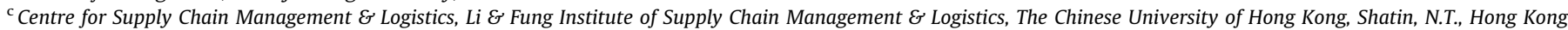 \\ ${ }^{\mathrm{d}}$ Department of Decision Sciences and Managerial Economics, Faculty of Business Administration, The Chinese University of Hong Kong, Shatin, N.T., Hong Kong
}

\section{A R T I C L E I N F O}

\section{Article history:}

Received 15 February 2008

Received in revised form 29 May 2009

Accepted 8 June 2009

Available online 17 June 2009

\section{Keywords:}

Supply chain integration

Taxonomy

Performance

China

Supply chain management

\begin{abstract}
A B S T R A C T
This study extends the developing body of literature on supply chain integration (SCI), which is the degree to which a manufacturer strategically collaborates with its supply chain partners and collaboratively manages intra- and inter-organizational processes, in order to achieve effective and efficient flows of products and services, information, money and decisions, to provide maximum value to the customer. The previous research is inconsistent in its findings about the relationship between $\mathrm{SCl}$ and performance. We attribute this inconsistency to incomplete definitions of SCI, in particular, the tendency to focus on customer and supplier integration only, excluding the important central link of internal integration. We study the relationship between three dimensions of $\mathrm{SCI}$, operational and business performance, from both a contingency and a configuration perspective. In applying the contingency approach, hierarchical regression was used to determine the impact of individual SCI dimensions (customer, supplier and internal integration) and their interactions on performance. In the configuration approach, cluster analysis was used to develop patterns of SCI, which were analyzed in terms of SCI strength and balance. Analysis of variance was used to examine the relationship between SCI pattern and performance. The findings of both the contingency and configuration approach indicated that SCI was related to both operational and business performance. Furthermore, the results indicated that internal and customer integration were more strongly related to improving performance than supplier integration.
\end{abstract}

(c) 2009 Elsevier B.V. All rights reserved.

\section{Introduction}

Researchers have long articulated the need for a close, integrated relationship between manufacturers and their supply chain partners (e.g., Lambert et al., 1978; Armistead and Mapes, 1993). However, only recently has there been a call for a systematic approach to supply chain integration (SCI), as increasingly global competition has caused organizations to rethink the need for cooperative, mutually beneficial supply chain partnerships (Lambert and Cooper, 2000; Wisner and Tan, 2000) and the joint improvement of inter-organizational processes has become a high priority (Zhao et al., 2008).

\footnotetext{
* Corresponding author. Tel.: +1 317278 8586; fax: +1 3172743312 .

E-mail addresses: bbflynn@iupui.edu (B.B. Flynn), bladehuo@hotmail.com (B. Huo), xiande@baf.msmail.cuhk.edu.hk (X. Zhao).

1 Tel.: +8523163 4493; fax: +85231634492.

2 Tel.: +852 2609 7650; fax: +852 26036840 .
}

The existing research on SCI, however, is characterized by evolving definitions and dimensions (Van der Vaart and van Donk, 2008). While some focuses on the individual dimensions of SCI (Cousins and Menguc, 2006; Homburg and Stock, 2004; Koufteros et al., 2007), in particular customer and supplier integration, others use various omnibus definitions (Armistead and Mapes, 1993; Rosenzweig et al., 2003), examining SCI as a single construct. In addition, many conceptualizations of SCI are incomplete, leaving out the important central link of internal integration.

These incomplete and evolving conceptualizations have led to inconsistent findings about the relationship between $\mathrm{SCI}$ and performance (e.g. Devaraj et al., 2007; Germain and Iyer, 2006; Das et al., 2006; Stank et al., 2001a). In order to fully understand SCI and its relationship to performance, there is a need to examine both how individual dimensions of $\mathrm{SCI}$ are related to different dimensions of performance, as well as how patterns of SCI are related to different dimensions of performance. This suggests taking both a contingency and a configuration approach to studying SCI, echoing the appeal of Harland et al. (2007). In particular, it is important to apply both approaches within a single 
study, in order to determine whether the findings are due to the relationship between $\mathrm{SCI}$ and performance or are an artifact of the data collection and survey design.

We build on this foundation, applying a contingency approach to examine the relationship between internal, customer and supplier integration and both operational and business performance. We suggest that customer and supplier integration moderate the relationship between internal integration and performance, building upon its foundation. We then apply a configuration approach to delve more deeply into how the dimensions of SCI work together, in order to continue to learn about how various SCI patterns are related to performance. In relating $\mathrm{SCI}$ patterns to performance, we examine both operational and business performance measures, which allows drawing more comprehensive conclusions.

An important question that this allows us to consider is whether SCI patterns that are either strong or balanced are more strongly related to specific performance measures, or whether organizations that have supply chains that are well integrated (strength) across the board (balance) will have better performance on all dimensions. These questions are important to decision makers because they provide insights about strategies for pursuing SCI.

\section{Theoretical background}

\subsection{Definition of $S C I$}

The SCI construct is relatively new as an area of research, although there is an extensive body of research on unidimensional supply chain relationships, examining collaborative relationships between a manufacturer and either its customers or suppliers (Paulraj et al., 2008; Mabert and Venkataramanan, 1998; Spekman et al., 1998; Fawcett and Magnan, 2002). While some focus on dyadic relationships with supply chain partners (Lee and Whang, 2001), others focus on managing a supply chain as a single system, rather than attempting to individually optimize fragmented subsystems (Vickery et al., 2003; Naylor et al., 1999; Bowersox and Morash, 1989; Hammer, 1990; Stevens, 1989). While some SCI definitions emphasize flows of materials and parts, others focus more on flows of information, resources and cash. Although these descriptions touch many of the critical elements of SCI, they are broad in focus. In addition, most fail to consider the strategic nature of SCI.

We build upon the existing literature on the SCI construct, including the manufacturer (internal integration) and extending from it both directions (customer and supplier integration), and building upon its gaps to develop a parsimonious definition of SCI. The term "integration" is defined as "the unified control of a number of successive or similar economic or especially industrial processes formerly carried on independently" (Webster's 1966, p. 1175). Applying this in a supply chain context, we define SCI as the degree to which a manufacturer strategically collaborates with its supply chain partners and collaboratively manages intra- and inter-organization processes. The goal is to achieve effective and efficient flows of products and services, information, money and decisions, to provide maximum value to the customer at low cost and high speed (Bowersox et al., 1999; Frohlich and Westbrook, 2001; Naylor et al., 1999).

This definition includes several important elements. First, we highlight the importance of strategic collaboration, which is an ongoing partnership to achieve mutually beneficial strategic goals. It engenders mutual trust, increases contract duration and encourages efficient conflict resolution and sharing of information, rewards and risks (Ellram, 1990; Heide and John, 1990; Poirier and Reiter, 1996). While operational coordination can only lead to operational benefits, strategic coordination provides both operational and strategic benefits (Sanders, 2008). This definition also emphasizes intra- and inter-organization processes, since SCI is comprehensive and encompasses a variety of activities, including many that are focused on materials, transportation and administrative tasks (Bowersox and Morash, 1989; Hillebrand and Biemans, 2003). Finally, we emphasize the customer-facing nature of SCI, stating that its primary objective is to provide maximum value for the customer.

\subsection{Dimensions of SCI}

Consideration of the dimensionality of SCI is important in understanding the way that the individual dimensions operate, as well as how they function jointly. Appendix A contains a summary of important previous studies investigating various dimensions of $\mathrm{SCI}$. While some authors investigated SCI as a unidimensional construct (Armistead and Mapes, 1993; Marquez et al., 2004; Rosenzweig et al., 2003), others have broken SCI into internal and external integration (Campbell and Sankaranl, 2005; Morash and Clinton, 1998; O'Leary-Kelly and Flores, 2002; Pagell, 2004; Petersen et al., 2005; Ragatz et al., 2002; Stank et al., 2001b; Stanley and Wisner, 2001; Zailani and Rajagopal, 2005), and some have taken an even broader perspective, including multiple dimensions (Droge et al., 2004; Gimenez and Ventura, 2005; Koufteros et al., 2005; Narasimhan and Kim, 2002; Stank et al., 2001a; Vickery et al., 2003). While each of these dimensions represents an important aspect of $\mathrm{SCI}$, there is a great deal of overlap between them, making it difficult to untangle their relationships.

We argue that the diverse dimensions of SCI can ultimately be collapsed into three dimensions: customer, supplier and internal integration. Customer and supplier integration are commonly referred to as external integration, which is the degree to which a manufacturer partners with its external partners to structure inter-organizational strategies, practices and processes into collaborative, synchronized processes (Stank et al., 2001b). Customer integration involves core competencies derived from coordination with critical customers, whereas supplier integration involves core competencies related to coordination with critical suppliers (Bowersox et al., 1999). In contrast, internal integration focuses on activities within a manufacturer. It is the degree to which a manufacturer structures its own organizational strategies, practices and processes into collaborative, synchronized processes, in order to fulfill its customers' requirements (Cespedes, 1996; Kahn and Mentzer, 1996; Kingman-Brundage et al., 1995) and efficiently interact with its suppliers.

Internal integration and external integration play different roles in the context of SCI. While internal integration recognizes that the departments and functions within a manufacturer should function as part of an integrated process, external integration recognizes the importance of establishing close, interactive relationships with customers and suppliers. Both perspectives are important in allowing supply chain members to act in a concerted way, to maximize the value of the supply chain.

\subsection{Contingency approach to $S C I$}

Contingency theory (Lawrence and Lorsch, 1967; Thompson, 1967) argues that no theory or method can be applied in all instances, in other words, that there is no one best way to design an organization (Scott and Cole, 2000). It employs a reductionist approach, treating an organization as decomposable into independent elements (Sinha et al., 2005). The environment that an organization operates within shapes its structures and processes. This suggests that organizations should match their structures and processes to their environment, in order to maximize performance (Donaldson, 2001; Lawrence and Lorsch, 1967), and customers and suppliers are an important part of a manufacturer's environment. 
Structural contingency theory (Chandler, 1962; Lawrence and Lorsch, 1967; Galbraith, 1973) suggests that how well an organization performs depends on the extent to which the strategy that it seeks to pursue is aligned with its design. This alignment between strategy and performance is described as "fit" in the strategic management literature (Drazin et al., 1985; Venkatraman and Prescott, 1990; Milgrom and Roberts, 1995). Applied to SCI, structural contingency theory suggests that the individual dimensions of SCI should be aligned, in order to achieve the best performance.

\subsubsection{Relationship between internal integration and performance}

Just as internal fit indicates consistency among structural characteristics within an organization (Drazin et al., 1985; Venkatraman and Prescott, 1990; Milgrom and Roberts, 1995), internal integration recognizes that different departments and functional areas within a firm should operate as part of an integrated process. Because internal integration breaks down functional barriers and engenders cooperation in order to meet the requirements of customers, rather than operating within the functional silos associated with traditional departmentalization and specialization, it is expected to be related to performance. Although manufacturers may maintain a functional organization structure, customer orders flow across functions and activities. When an order is delayed, customers do not care which function caused the delay; they simply want to know whether the order has been fulfilled. This calls for an integrated customer order fulfillment process, in which all involved activities and functions work together. Information sharing, joint planning, cross-functional teams and working together are important elements of this process.

Selecting the appropriate performance measures is challenging, due to the inherent complexity and interdependence of supply chains. While Chen and Paulraj (2004a) argued that financial performance should be the main measure of SC performance because of the shareholder profit motive, others have described the limitations of relying solely on financial measures of performance (Dixon et al., 1990; Eccles and Pyburn, 1992; Hall, 1983; Johnson and Kaplan, 1987; Skinner, 1971). Van Hoek (1998) and Beamon (1999) suggested that SC performance measurement should include operational indicators, such as customer service and the ability to respond to a changing environment. Neely et al. (1995) listed cost, time, quality, delivery and flexibility as important measures of operational performance.

Although some authors found no direct relationship between internal integration and operational performance (Koufteros et al., 2005; Gimenez and Ventura, 2005), others found a positive relationship between internal integration and operational performance, including process efficiency (Saeed et al., 2005) and logistics service performance (Germain and Iyer, 2006; Stank et al., 2001a,b). We argue that internal integration is the base for SCI and will be positively related to operational performance. Thus, we propose:

H1a. Internal integration is positively related to the operational performance of the manufacturer within a supply chain.

Stank et al. (2001b) described internal and customer integration as the most significant differentiators of overall firm performance, and although the literature on the relationship between SCI and business performance is quite extensive (e.g. Droge et al., 2004; Frohlich and Westbrook, 2001, 2002; O'Leary-Kelly and Flores, 2002; Rosenzweig et al., 2003; Swink et al., 2007; Zailani and Rajagopal, 2005), it is inconclusive. For example, while Droge et al. (2004) found that both internal and external integration were related to financial performance and market share, Swink et al. (2007) found that the individual dimensions of SCI had differing impacts on business performance. More typical are studies that indirectly link SCI to business performance, for example, through improved product innovation (Koufteros et al., 2005) or operational performance, or through a mediated or moderated relationship (Vickery et al., 2003; Rosenzweig et al., 2003; O'Leary-Kelly and Flores, 2002). Thus, we propose:

H1 $1_{\text {b. }}$ Internal integration is positively related to the business performance of the manufacturer within a supply chain.

\subsubsection{Relationship of customer and supplier integration to performance}

According to structural contingency theory, external fit indicates consistency between an organizational structure and the strategy it pursues in response to its external environment. As its external environment (in a supply chain, the characteristics of its customers and suppliers) changes, a manufacturer should respond by developing, selecting and implementing strategies to maintain fit, not only among internal structural characteristics, but also with its external environment (Hambrick, 1983; Kotha and Nair, 1995; Tushman and Nadler, 1978). Thus, customer and supplier integration build on a manufacturer's internal integration to form an important element of $\mathrm{SCI}$.

A close relationship between customers and the manufacturer offers opportunities for improving the accuracy of demand information, which reduces the manufacturer's product design and production planning time and inventory obsolescence, allowing it to be more responsive to customer needs. Because customer integration generates opportunities for leveraging the intelligence embedded in collaborative processes, it enables manufacturers to reduce costs, create greater value and detect demand changes more quickly. Customer integration has been found to be related to customer satisfaction, both directly (Homburg and Stock, 2004) and indirectly, through its relationship to product development and innovation (Koufteros et al., 2005; Song and Di Benedetto, 2008).

In an integrated supply chain, development of a strong strategic partnership with suppliers will facilitate their understanding and anticipation of the manufacturer's needs, in order to better meet its changing requirements. This mutual exchange of information about products, processes, schedules and capabilities helps manufacturers develop their production plans and produce goods on time, improving delivery performance. By developing a good understanding of the manufacturer's operations, suppliers achieve a high level of customer service, which, in turn, helps the manufacturers improve their customer service. Supplier integration has been found to be related to product development performance (Petersen et al., 2005; Koufteros et al., 2007; Ragatz et al., 2002) and supplier communications performance (Cousins and Menguc, 2006). Others, however, have found no relationship between supplier integration and operational performance (Stank et al., 2001b) or a negative relationship (Koufteros et al., 2005; Stank et al., 2001a; Swink et al., 2007).

The work of stage theorists suggests that internal integration is a prerequisite for both customer and supplier integration (Morash and Clinton, 1998). Their argument rests on the notion that external uncertainties and linkages must be internally absorbed into the proper places in an organization and that the primary impediment to achieving the benefits of external SCI is intraorganizational barriers to internal integration. Customer and supplier integration extend internal integration's elimination of functional silos to span across organizational boundaries. Thus,

H2a. Customer and supplier integration are positively related to the operational performance of the manufacturer within a supply chain, given the relationship between internal integration and operational performance. 
H2 . Customer and supplier integration are positively related to the business performance of the manufacturer within a supply chain, given the relationship between internal integration and business performance.

\subsubsection{Moderating effects}

Contingency theory also suggests that individual dimensions of SCI will interact to affect performance. A manufacturer's efforts in external supplier and customer integration help it take full advantage of its internal integration, in order to achieve better operational performance.

Germain and Iyer (2006) found that the interaction between internal integration and customer integration was related to logistics performance, which in turn was related to financial performance. Droge et al. (2004) found that internal integration moderated the effect of external integration on performance, and Devaraj et al. (2007) found that customer integration moderated the relationship between supplier integration and performance. We hypothesize two- and three-way interactions between the dimensions of SCI.

H3a. Customer and supplier integration will moderate the relationship between internal integration and operational performance.

$\mathbf{H 3}_{\mathbf{b}}$. Customer and supplier integration will moderate the relationship between internal integration and business performance.

\subsection{Configuration approach}

Although the perspectives provided by the contingency approach contribute to the knowledge about SCI, this approach is somewhat limited. While it allows detailed examination of the relationship between the dimensions of SCI and performance, its reductionism causes it to be unable to handle complicated organizational phenomena from a holistic perspective. Because an organization is composed of many contingencies (Siggelkow, 2001; Sinha et al., 2005), drawing conclusions about specific contingent relationships can be challenging. Results from a contingency approach can also be difficult to interpret when some of the interactions are nonsignificant. A third issue related to the contingency approach is the multicollinearity between the independent variables that comprise a related construct like SCI that is often present.

This suggests that additional analysis, based on a configuration perspective, will be useful in analyzing the relationship between $\mathrm{SCI}$ and performance. Configuration theory describes an organization as a set of interrelated activities. Rather than the pairwise relationships that the contingency approach focuses on, a configuration approach views fit in terms of "gestalts" or configurations of various elements and their relationships (Drazin et al., 1985). The configuration approach argues that, when organizational elements are consistent with each other, a holistic, rather than piecemeal, analysis should be applied (Miller, 1986; Ward et al., 1996). This approach is very useful in handling the coalignment or fit among multiple variables, such as the dimensions of $\mathrm{SCI}$, and it is appropriate for handling complex relationships.

\subsubsection{Configurations of $\mathrm{SCI}$}

The configuration approach focuses on establishing patterns or profiles. According to configuration theory (Miller, 1986), the alignment of strategy and systems or practices is reflected in the patterns observed in practice. This suggests a need to articulate emergent patterns of SCI. The inductive configuration approach is data driven, applying an analytical approach to empirically develop a taxonomy. Taxonomies contribute to both theory and practice by providing "parsimonious descriptions which are useful in discussion, research and pedagogy" (Miller and Roth, 1994, p. 286) and revealing "insights into the underlying structures of competition from the viewpoint of operations" (Zhao et al., 2006b, p. 622). They allow for the possibility of other patterns, which may have not been part of a theoretical typology, to emerge.

Frohlich and Westbrook (2001) developed a taxonomy of different patterns or "arcs" of SCI and showed that they were related to performance differences. Their taxonomy included five types, including inward-, periphery- supplier-, customer- and outward-facing SCI types. It was based only on customer and supplier integration; it did not consider internal integration. In addition, their cutoff points were based on quartiles, so there are not necessarily significant gaps between members of different groups. This suggests that an analytical grouping approach that develops groups based on significant gaps between them, such as cluster analysis, may lead to a better understanding of various SCI patterns and how they are related to performance.

Since different companies may place differing degrees of emphasis on the individual dimensions of SCI, various configurations of $\mathrm{SCl}$ exist. These patterns can be described in terms of their SCI strength and balance. SCI strength is the level or extent to which SCI activities are carried out. Many previous studies (Frohlich and Westbrook, 2001; Narasimhan and Kim, 2002; Petersen et al., 2005; Devaraj et al., 2007) have measured the strength of SCI, providing a benchmark for comparison. In contrast, SCI balance is the extent to which a company pays equal attention to all three dimensions of $\mathrm{SCl}$. The literature indicates that manufacturers may not place equal emphasis on every dimension of SCI. While some may have well integrated internal systems, they may not have extended this approach to customers and suppliers, while others may be strong in customer or supplier integration and weaker in their internal integration.

There is a need for a taxonomy which is based on significant gaps between the groups, in order to have better insights about the relationship between SCI patterns and performance. In addition, the literature is notably lacking a taxonomy of SCI that incorporates internal integration, as well as customer and supplier integration. Thus, we propose:

H4. An emergent taxonomy of manufacturers can be developed, based on their patterns of supplier, internal and customer integration.

\subsubsection{Impact of SCI patterns on performance}

Configuration theory suggests that the emergent patterns of SCI will be related to operational performance in different ways. It argues that organizations perform better when they develop better configurations of interconnected elements (Drazin et al., 1985; Sinha et al., 2005). For example, a SCI pattern which is stronger in customer integration is likely to have a stronger relationship to customer satisfaction than a pattern which is stronger in supplier integration. Furthermore, the relationship of SCI to performance may be determined by the pattern $\mathrm{SCI}$, in terms of the strength and balance of the three dimensions. Therefore, we propose:

H5 a. The patterns of $\mathrm{SCI}$ are related to the operational performance of the manufacturer within a supply chain.

Adding internal integration to the dimensions that Frohlich and Westbrook (2001) used in their taxonomy is expected to yield similar results, in terms of their relationship with performance, thus, we expect that manufacturers with the strongest overall SCI will have the best business performance. Supplier and internal integration help manufacturers reduce mistakes and waste, 
through information sharing and joint planning, which is directly related to business performance. Customer integration will help the manufacturer better understand customer requirements and better forecast customer demand, thus allowing the manufacturer to provide better quality products at lower cost and more flexibly. These will, in turn, lead to better financial performance by the manufacturer. Furthermore the effectiveness of SCI will be related to configuration of the three $\mathrm{SCI}$ dimensions. Thus, we propose:

$\mathbf{H 5}_{\mathbf{b}}$. The patterns of $\mathrm{SCI}$ are related to the business performance of the manufacturer within a supply chain.

\section{Research methodology}

\subsection{Questionnaire design and measures}

We surveyed the literature to identify valid measures for related constructs and adapted existing scales to measure internal integration (Narasimhan and Kim, 2002), customer and supplier integration (Narasimhan and Kim, 2002; Morash and Clinton, 1998), operational performance (Frohlich and Westbrook, 2001; Beamon, 1999; Vickery et al., 2003) and business performance (Narasimhan and Kim, 2002). When there were no reliable and valid existing measures, we developed new measures, based on our understanding of the constructs and our observations during company visits and interviews. The indicators were all measured using a seven-point Likert scale, where higher values indicated stronger integration or better performance. The complete scales are listed in Appendix B.

Since the scales drawn from the literature were in English, the initial questionnaire was developed in English, then translated into Chinese by an operations management professor in China. The Chinese version was then translated back into English by another operations management professor, and the translated English version was checked against the original English version for discrepancies. In mainland China, we used the Chinese version of the questionnaire. In Hong Kong, a bilingual version of the questionnaire was used.

There were two preliminary assessments of the questionnaire. First, we submitted the questionnaire to academicians and supply chain executives for their review. Next, we pre-tested it in a sample of fifteen companies, which we visited to conduct face-to-face discussions. Based on the feedback, we modified the wording of some questions and added or deleted some, in order to ensure that the items were understandable and relevant to practices in China.

\subsection{Sampling and data collection}

Data were collected from manufacturing companies in China. Because of China's size and economic diversity (Zhao et al., 2006a), we strategically selected five cities representing different stages of economic development. Chongqing is in the early stages of economic reform and market formation, while Tianjin reflects an average level. Guangzhou and Shanghai have enjoyed a higher degree of economic reform and marketization, and Hong Kong is one of the freest economies in the world. Although most Hong Kong companies house their manufacturing operations in mainland China, they use Hong Kong as the hub from which to control and direct the flows of materials, finished goods, information, logistics and money.

The research unit was the manufacturing company and its supply chain. To obtain a representative sample, we used the Yellow Pages of China Telecom in each of the four mainland China cities and the directory of the Chinese Manufacturers Association in Hong Kong as our sampling pool. For each randomly selected manufacturer, we identified a key informant, who typically had a title such as supply chain manager, CEO/president, vice president or director, and was knowledgeable about the company's internal and external processes. We contacted the key informants by telephone, in order to obtain their preliminary agreement to participate.

We mailed the questionnaire, along with a cover letter highlighting the study's objectives and potential contributions. Follow-up telephone calls and mailings were used to improve the response rate (Frohlich, 2002) and address potential missing data issues. Out of 4569 companies contacted, a total of 1356 questionnaires were distributed, and there were 617 usable questionnaires returned. The response rate was $13.5 \%$ based on the number of companies contacted via telephone and $45.5 \%$ based on the number of questionnaires distributed, comparable to other SCI studies (Devaraj et al., 2007; Koufteros et al., 2005; Rosenzweig et al., 2003; Swink et al., 2007). A profile of the respondents is presented in Tables 1 and 2, indicating that they represent a variety of industries and their distribution is representative of the

Table 1

Profiles of responding companies.

\begin{tabular}{|c|c|c|c|c|c|c|}
\hline & $\begin{array}{l}\text { Overall } \\
n=617\end{array}$ & $\begin{array}{l}\text { Hong Kong } \\
n=206\end{array}$ & $\begin{array}{l}\text { Guangzhou } \\
n=104\end{array}$ & $\begin{array}{l}\text { Chongqing } \\
n=104\end{array}$ & $\begin{array}{l}\text { Shanghai } \\
n=100\end{array}$ & $\begin{array}{l}\text { Tianjin } \\
n=103\end{array}$ \\
\hline Industries & \multicolumn{6}{|c|}{ Percentage distribution } \\
\hline Arts and crafts & $1.9 \%$ & $0.5 \%$ & $3.8 \%$ & $4.8 \%$ & $1.0 \%$ & $1.0 \%$ \\
\hline Building materials & 5.0 & 1.9 & 6.7 & 8.7 & 7.0 & 3.9 \\
\hline Chemicals and petrochemicals & 6.3 & 1.5 & 8.7 & 7.7 & 8.0 & 10.7 \\
\hline Electronics and electrical & 13.1 & 13.6 & 9.6 & 11.5 & 11.0 & 19.4 \\
\hline Food, beverage and alcohol & 4.9 & 5.8 & 5.8 & 4.8 & 1.0 & 5.8 \\
\hline Jewelry & 0.5 & 1.0 & 0.0 & 0.0 & 0.0 & 1.0 \\
\hline Metal, mechanical and engineering & 25.4 & 9.2 & 28.8 & 35.6 & 42.0 & 28.2 \\
\hline Pharmaceutical and medical & 1.8 & 2.4 & 0.0 & 3.8 & 0.0 & 1.9 \\
\hline Publishing and printing & 4.4 & 2.4 & 1.9 & 9.6 & 7.0 & 2.9 \\
\hline Rubber and plastics & 6.6 & 9.2 & 2.9 & 2.9 & 8.0 & 7.8 \\
\hline Textiles and apparel & 17.8 & 35.4 & 14.4 & 3.8 & 10.0 & 7.8 \\
\hline Toys & 1.3 & 3.9 & 0.0 & 0.0 & 0.0 & 0.0 \\
\hline Wood and furniture & 1.9 & 1.0 & 3.8 & 1.9 & 0.0 & 3.9 \\
\hline Sales & \multicolumn{6}{|c|}{ Percentage distribution } \\
\hline$<\mathrm{HK} \$ 5 \mathrm{M}$ & $32.4 \%$ & $9.1 \%$ & $49.0 \%$ & $33.7 \%$ & $30.0 \%$ & $56.3 \%$ \\
\hline HK\$5-10M & 14.1 & 9.1 & 18.3 & 12.5 & 16.0 & 18.4 \\
\hline HK\$10-20M & 12.4 & 15.3 & 4.8 & 19.2 & 12.0 & 8.7 \\
\hline HK\$20-50M & 15.8 & 22.2 & 12.5 & 16.3 & 15.0 & 8.6 \\
\hline HK\$50-100M & 10.2 & 13.6 & 9.6 & 7.7 & 15.0 & 2.9 \\
\hline HK\$100 or more & 15.0 & 30.7 & 5.8 & 10.6 & 12.0 & 4.9 \\
\hline
\end{tabular}


Table 2

Respondent characteristics.

\begin{tabular}{llll}
\hline Position & $\begin{array}{l}\text { \% of } \\
\text { respondents }\end{array}$ & $\begin{array}{l}\text { Years in current } \\
\text { position }\end{array}$ & $\begin{array}{l}\text { \% of } \\
\text { respondents }\end{array}$ \\
\hline Top management & $39.9 \%$ & $1-3$ years & $26.9 \%$ \\
Middle management & 56.9 & $4-6$ years & 22.9 \\
Other & 3.2 & $\begin{array}{l}7-12 \text { years } \\
\text { More than 12 years }\end{array}$ & $\begin{array}{l}24.6 \\
\end{array}$ \\
\hline
\end{tabular}

concentration of industries in the cities studied. Most of the respondents have been in their position for more than three years; thus, they should be knowledgeable about the information requested.

To assess potential late response bias, we compared early and late responses on their physical assets, annual sales and number of employees (Armstrong and Overton, 1977), with a $t$-test showing no significant differences. Since there was a single informant per organization, the potential for common method bias was assessed. Analysis of Harmon's single-factor test of common method bias (Podsakoff and Organ, 1986; Podsakoff et al., 2003; Hochwarter et al., 2004) revealed nine distinct factors with eigenvalues above or near 1.0 , explaining $72.1 \%$ total variance. The first factor explained $33.8 \%$ of the variance, which was not the majority of the total variance. It is acceptable for a study such as this, where the constructs are correlated, both conceptually and practically. To further assess common method bias, confirmatory factor analysis was applied to Harman's single-factor model (Sanchez and Brock, 1996). The model's fit indices of $\chi^{2}(986)=11690.67$, NNFI $=0.85$, $\mathrm{CFI}=0.86$, RMSEA $=0.18$ and SRMR $=0.13$ were unacceptable and were significantly worse than those of the measurement model. This suggests that a single factor is not acceptable, thus the common method bias is small. As a third test of common method bias, a measurement model including only the traits and one including a method factor, in addition to the traits, were tested (Widaman, 1985; Paulraj et al., 2008; Podsakoff et al., 2003; Williams et al., 1989). The results of the method factor model marginally improved model fit (NFI by 0.01 , NNFI by 0.01 , CFI 0.01 ), with the common method factor accounting for $10.2 \%$ of the total variance. The path coefficients of the trait factors and their significance were similar between the two models, suggesting that they were robust, despite the inclusion of a method factor (Paulraj et al., 2008). This provides further indication that the common method bias is not a serious concern.

\subsection{Reliability and validity}

Each variable's cumulative proportion was plotted against the cumulative proportion for several test distributions, revealing that the data appeared to be approximately normally distributed. The scales were all reliable, with alpha values ranging from 0.84 to 0.94 (see Table 3). Appendix B reveals that all items had strong loadings on the construct that they were intended to measure. The EFA results also indicate that all items have lower loadings on the constructs that they were not intended to measure. The results demonstrate construct unidimensionality. Content validity was established through a domain search of the literature, careful synthesis and critical evaluation of existing constructs and an iterative construct review by domain experts.

We first used CFA to evaluate convergent validity as suggested by O'Leary-Kelly and Vokurka (1998). Each measurement item was linked to its corresponding construct, and the covariance among the constructs was freely estimated. The model fit indices were $\chi^{2}$ $(976)=4751.23, \quad$ NNFI $=0.95, \quad$ CFI $=0.95, \quad$ RMSEA $=0.090$ and $\mathrm{SRMR}=0.070$. Thus, the model was acceptable (Hu and Bentler, 1999), indicating convergent validity (O'Leary-Kelly and Vokurka, 1998). Furthermore, all factor loadings were greater than 0.50 , the $t$-values were all greater than 2.0 (Droge et al., 2004; Koufteros et al., 2007; Narasimhan and Kim, 2002; Vickery et al., 2003), and each item's coefficient is greater than twice its standard error (Anderson and Gerbing, 1988), further demonstrating convergent validity. The estimates for the average variance extracted (AVE) were higher than 0.50 for four constructs, and 0.46 for the fifth construct. While Fornell and Larcker (1981) suggested that the minimum AVE should be 0.50 and one of our constructs fall slightly below the minimum of 0.50 , we satisfied the more detailed criteria set by several other studies as indicated above. Therefore our constructs have convergent validity.

In order to assess discriminant validity, we built a constrained CFA model for every possible pair of latent constructs, in which the correlations between the paired constructs were fixed to 1.0. This was compared with the original unconstrained model, in which the correlations among constructs were freely estimated. The $\chi^{2}$ difference demonstrated discriminant validity (Bagozzi et al., 1991; Chen and Paulraj, 2004b; O'Leary-Kelly and Vokurka, 1998). Furthermore, the average variance extracted (AVE) for each construct was greater than the squared correlation between that construct and the other constructs as suggested by Fornell and Larcker (1981), providing further evidence of discriminant validity.

\section{Results}

\subsection{Contingency analysis of SCI}

Hierarchical regression analysis was used to test hypotheses 13. In the first step, the direct effect of internal integration on operational and business performance was assessed. In the second step, we assessed the relationship of customer and supplier integration to operational or business performance, given the relationship between internal integration and operational or

Table 3

Descriptive statistics.

\begin{tabular}{|c|c|c|c|c|c|c|}
\hline & \multicolumn{5}{|c|}{ Correlation coefficients } & \multirow[t]{2}{*}{ Cronbach's alpha } \\
\hline & $\begin{array}{l}\text { Supplier } \\
\text { integration }\end{array}$ & $\begin{array}{l}\text { Internal } \\
\text { integration }\end{array}$ & $\begin{array}{l}\text { Customer } \\
\text { integration }\end{array}$ & $\begin{array}{l}\text { Operational } \\
\text { performance }\end{array}$ & $\begin{array}{l}\text { Business } \\
\text { performance }\end{array}$ & \\
\hline Supplier integration & 1.00 & & & & & 0.94 \\
\hline Internal integration & $0.52^{* * *}$ & 1.00 & & & & 0.92 \\
\hline Customer integration & $0.65^{* * *}$ & $0.59^{* * *}$ & 1.00 & & & 0.90 \\
\hline Operational performance & $0.31^{* * *}$ & $0.40^{* * *}$ & $0.46^{* * *}$ & 1.00 & & 0.86 \\
\hline Business performance & $0.22^{* * *}$ & $0.35^{* * *}$ & $0.25^{* * *}$ & $0.31^{* * *}$ & 1.00 & 0.94 \\
\hline Mean & 3.51 & 4.05 & 4.26 & 5.43 & 3.99 & \\
\hline Standard deviation & 1.41 & 1.45 & 1.26 & .97 & 1.16 & \\
\hline
\end{tabular}

${ }^{*} p<0.05$. ${ }^{* *} p<0.01$. $p<0.001$. 
Table 4

Regression results for operational performance.

\begin{tabular}{|c|c|c|c|c|c|c|}
\hline Model & Independent variables & $\beta$ & $t$ & $R^{2}$ & $F$ & $\Delta R^{2}$ \\
\hline 1 & $\begin{array}{l}\text { Constant } \\
\text { Internal integration }\end{array}$ & $\begin{array}{r}4.34 \\
.27\end{array}$ & $\begin{array}{l}40.78^{* * *} \\
10.94^{* * *}\end{array}$ & .163 & $119.58^{* * *}$ & - \\
\hline 2 & $\begin{array}{l}\text { Constant } \\
\text { Internal integration } \\
\text { Customer integration } \\
\text { Supplier integration }\end{array}$ & $\begin{array}{r}3.78 \\
.14 \\
.27 \\
-.02\end{array}$ & $\begin{array}{c}30.10^{* * *} \\
4.62^{* * *} \\
6.97^{* * *} \\
-.57\end{array}$ & .237 & $63.51^{* * *}$ & .074 \\
\hline 3 & $\begin{array}{l}\text { Constant } \\
\text { Internal integration } \\
\text { Customer integration } \\
\text { Supplier integration } \\
\mathrm{II} \times \mathrm{CI} \text { interaction } \\
\mathrm{II} \times \mathrm{SI} \text { interaction } \\
\mathrm{CI} \times \mathrm{SI} \text { interaction } \\
\mathrm{II} \times \mathrm{CI} \times \mathrm{SI} \text { interaction }\end{array}$ & $\begin{array}{r}3.55 \\
.16 \\
.30 \\
-.03 \\
.00 \\
.00 \\
-.06 \\
-.01\end{array}$ & $\begin{array}{c}19.90^{* * *} \\
4.75^{* * *} \\
7.47^{* * *} \\
-.93 \\
.15 \\
.10 \\
2.50^{*} \\
-.73\end{array}$ & .255 & $29.71^{* * *}$ & .017 \\
\hline
\end{tabular}

$p<0.05,{ }^{* *} p<0.01$

$p<0.001$.

business performance. The third step assessed the relationship between two- and three-way interactions of internal, customer and supplier integration and operational or business performance, in order to determine whether there was a moderating effect.

The results of the hierarchical regression analysis for operational and business performance are contained in Tables 4 and 5 . Table 4 indicates that there is a significant direct relationship between internal integration and operational performance, supporting $\mathrm{H} 1_{\mathrm{a}}$. Adding customer and supplier integration to the model yielded a significant change in $R^{2}$, indicating that the addition of customer and supplier integration contributed significantly to the predictive power of the model. However, only the coefficient for customer integration was statistically significant, indicating that customer integration was directly related to operational performance, given the relationship between internal integration and operational performance, while supplier integration was not. Therefore, the results only partially supported hypothesis $\mathrm{H}_{2}$ a.

Adding the interaction terms further increased the predictive power of the regression model, which was statistically significant. However, the interactions between customer or supplier integration and internal integration were not statistically significant, while there was a significant interaction between customer and supplier integration. Therefore, neither customer integration nor supplier integration moderated the relationship between internal integration and operational performance, and $\mathrm{H}_{\mathrm{a}}$ was not supported.
Table 5 indicates that there is a direct positive relationship between internal integration and business performance, supporting $\mathrm{H} 1_{\mathrm{b}}$. The addition of customer and supplier integration in step 2 added very little to the predictive power of the model, and the change in $R^{2}$ was not significant. Similarly, the addition of the interaction terms in step 3 had very little effect. Thus $\mathrm{H} 2_{b}$ and $\mathrm{H} 3_{b}$ were not supported. Although internal integration was related to business performance, customer integration, supplier integration and their interactions were not.

\subsection{Configuration analysis of SCI}

\subsubsection{Emergent taxonomy of SCI}

$\mathrm{H} 4$ posits that an emergent taxonomy can be developed, based on the internal, supplier and customer integration of manufacturers. Cluster analysis was used to classify the respondents into SCI patterns. Hierarchical clustering procedures determined the number of clusters that should be formed, then non-hierarchical clustering was applied to produce the final clusters (Hair et al., 1998). The percentage of change in the agglomeration coefficient was highest when the number of groups changed from five to four, indicating that five clusters were sufficient (Fig. 1). A random sampling of dendrograms confirmed that classification using five clusters represented the best solution.

In interpreting the results in Table 6 and Fig. 2, we examined SCI strength and balance. Two of the SCI patterns were stronger in

Table 5

Regression results for business performance.

\begin{tabular}{|c|c|c|c|c|c|c|}
\hline Model & Independent variables & $\beta$ & $t$ & $R^{2}$ & $F$ & $\Delta R^{2}$ \\
\hline 1 & $\begin{array}{l}\text { Constant } \\
\text { Internal integration }\end{array}$ & $\begin{array}{r}2.85 \\
.28\end{array}$ & $\begin{array}{l}21.91^{* * *} \\
9.29^{* * *}\end{array}$ & .123 & $86.24^{* * *}$ & - \\
\hline 2 & $\begin{array}{l}\text { Constant } \\
\text { Internal integration } \\
\text { Customer Integration } \\
\text { Supplier integration }\end{array}$ & $\begin{array}{r}2.73 \\
.25 \\
.04 \\
.03\end{array}$ & $\begin{array}{c}17.00^{* * *} \\
6.42^{* * *} \\
.78 \\
.60\end{array}$ & .126 & $29.38^{* * *}$ & .003 \\
\hline 3 & $\begin{array}{l}\text { Constant } \\
\text { Internal integration } \\
\text { Customer integration } \\
\text { Supplier integration } \\
\mathrm{II} \times \mathrm{CI} \text { interaction } \\
\mathrm{II} \times \mathrm{SI} \text { interaction } \\
\mathrm{CI} \times \mathrm{SI} \text { interaction } \\
\mathrm{II} \times \mathrm{CI} \times \mathrm{SI} \text { interaction }\end{array}$ & $\begin{array}{r}2.53 \\
.27 \\
.05 \\
.05 \\
.02 \\
.01 \\
-.03 \\
-.01\end{array}$ & $\begin{array}{c}11.00^{* * *} \\
6.33^{* * *} \\
.87 \\
1.02 \\
.71 \\
.29 \\
-.96 \\
-1.08\end{array}$ & .131 & $13.08^{* * *}$ & .005 \\
\hline
\end{tabular}

${ }^{*} p<0.05 .{ }^{* *} p<0.01$.

$p<0.001$. 


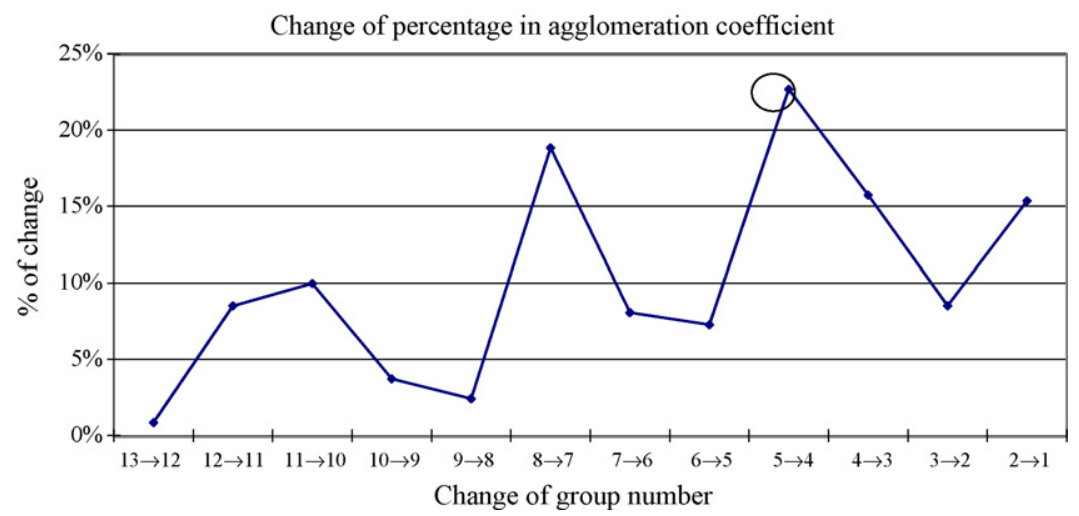

Fig. 1. Change of percentage in agglomeration coefficient.

Table 6

Cluster centroids.

\begin{tabular}{|c|c|c|c|c|}
\hline & Supplier integration & Internal integration & Customer integration & $n$ \\
\hline Low uniform & 1.83 & 2.02 & 2.66 & 111 \\
\hline Medium uniform & 4.06 & 3.38 & 4.28 & 151 \\
\hline High uniform & 5.47 & 5.43 & 5.67 & 111 \\
\hline Medium customer leaning & 2.36 & 4.16 & 3.63 & 108 \\
\hline High customer leaning & 3.59 & 5.24 & 4.87 & 136 \\
\hline$F$ & $492.03^{* * *}$ & $400.66^{* * *}$ & $244.55^{* * *}$ & \\
\hline
\end{tabular}

$p<0.05 .{ }^{* *} p<0.01$.

$p<0.001$.

internal and customer integration than they were in supplier integration. We labeled these the Medium Customer Leaning and High Customer Leaning SCI patterns and describe them as unbalanced SCI patterns. The other three SCI patterns were balanced, with similar levels of customer, supplier and internal integration within each pattern. We labeled these the Low Uniform, Medium Uniform and High Uniform SCI patterns, reflecting their balance between customer, supplier and internal integration. Canonical discriminant analysis was used to identify the underlying dimensions which defined the clusters. Table 7 shows that the first two functions had eigenvalues larger than 1 , explaining $99.9 \%$ of the variance. Table 8 reveals that all three dimensions of SCI were important in forming Function 1, which divided the clusters into those with low (Low Uniform), medium (Medium Customer Leaning and Medium Uniform patterns) and high SCI (High Customer Leaning and High Uniform patterns). Thus, Function 1 represents SCI strength, and it was the greatest differentiator between the patterns.

Function 2 reflects $\mathrm{SCI}$ balance, indicated by the positive loading of customer and internal integration and negative loading of supplier integration. It divides the patterns into those with greater (High, Medium and Low Uniform patterns) and less (High and Medium Customer Leaning patterns) SCI balance. Although statistically significant, this difference between the patterns was

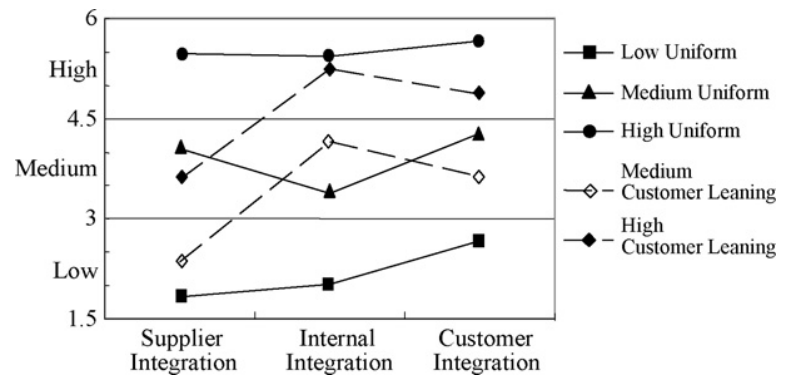

Fig. 2. Taxonomy of supply chain integration. weaker than their difference in SCI strength. Fig. 3 indicates that the clusters were differentiated from each other by the discriminant functions representing SCI strength and SCI balance. Between $96.3 \%$ and $98.7 \%$ of the respondents were correctly classified, indicating very high predictive ability. Thus, these patterns of SCI are independent and are not prone to misclassification. We conclude that manufacturers can be clustered into groups with differing levels of SCI strength and balance, based on customer, supplier and internal integration, supporting $\mathrm{H} 4$.

\subsubsection{Relationship between SCI patterns and performance}

Analysis of variance was used to test the relationship between SCI patterns and performance. Table 9 indicates that there were statistically significant differences in operational performance between the SCI patterns, supporting $\mathrm{H} 5$ a. Scheffe post hoc analysis was used to determine differences between specific patterns. The High Uniform pattern had the best operational performance, followed by the High Customer Leaning pattern. This indicates that $\mathrm{SCI}$ strength was more strongly related to operational performance than SCI balance. Interestingly, there was not a significant difference in operational performance between the High Uniform and High Customer Leaning patterns of SCI. Similarly, there was not a significant difference in operational performance among the Medium Uniform, Low Uniform, and Medium Customer Leaning patterns of SCI.

Table 9 also shows the relationship between SCI pattern and business performance, revealing that the High Uniform and High

Table 7

Discriminant analysis.

\begin{tabular}{lllll}
\hline Function & Eigenvalue & \% of variance & Cumulative \% & Canonical correlation \\
\hline 1 & 5.862 & $84.7 \%$ & $84.7 \%$ & $0.924^{* * *}$ \\
2 & 1.055 & 15.2 & 99.9 & $0.717^{* * *}$ \\
3 & 0.007 & 0.1 & 100.0 & 0.086 \\
\hline${ }^{*} p<0.05 .^{* * *} p<0.01$. & & & \\
& & &
\end{tabular}


Table 8

Standardized canonical discriminant function coefficients.

\begin{tabular}{llr}
\hline & Function 1 & Function 2 \\
\hline Customer integration & 0.490 & 0.047 \\
Supplier integration & 0.613 & -0.708 \\
Internal integration & 0.538 & 0.779 \\
\hline
\end{tabular}

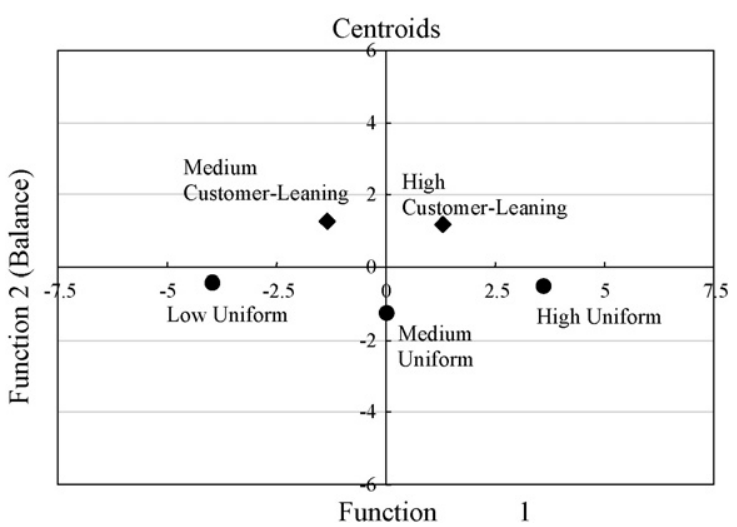

Fig. 3. Cluster centroids.

Customer Leaning patterns had the best business performance, and that there was no significant difference between them, supporting $\mathrm{H} 5$ b. The Low Uniform pattern of SCI had the worst business performance score. Integration strength was more important than integration balance in business performance.

\section{Discussion}

We found that most of our hypotheses were supported or partially supported, broadly indicating that SCI is related to performance. Specifically, by applying the contingency approach, we found that internal integration was directly related to both business and operational performance and that customer integration was directly related to operational performance. Although supplier integration was not directly related to either type of performance, the interaction of supplier and customer integration was related to operational performance.

When we compare our results with those from previous research on SCI, our finding that internal integration was significantly related to operational and business performance is consistent with several studies (Droge et al., 2004; Stank et al., 2001a,b; Germain and Iyer, 2006). Thus, our research reinforces the importance of internal integration in improving performance. This is an important finding, since much of the extant literature on $\mathrm{SCI}$ does not include internal integration as a dimension of SCI. Our finding that customer integration was significantly related to operational performance is consistent with the findings of several previous studies (Germain and Iyer, 2006; Koufteros et al., 2005). However, Devaraj et al. (2007) found that customer integration did not have a significant direct effect on operational performance, but only moderated the effect of supplier integration on operational performance. Our finding that supplier integration is not directly related to operational performance is supported by Stank et al. (2001a). In general, the literature on the relationship of supplier integration with performance has very mixed findings. While some studies (Koufteros et al., 2005; Swink et al., 2007) found that supplier integration was negatively related to certain aspects of operational performance, Devaraj et al. (2007) found a positive relationship between supplier integration and operational performance.

The comparison of our research findings with those of previous studies indicates that examination of the effect of the individual dimensions of SCI on performance was not sufficient. The relationship of SCI to performance can only be fully examined when all three dimensions of SCI are considered together. Studies which consider only one or two dimensions of SCI often lead to confusing results. For example, our analysis showed that supplier integration, in isolation, was significantly related to operational and business performance, however, this analysis did not consider internal integration. The relationship between supplier integration and operational and business performance became insignificant when internal integration was added to the model. Furthermore, supplier and customer integration often have different relationships to performance. Therefore, studies that aggregate supplier and customer integration in a single construct (external integration) may be drawing inaccurate conclusions.

Our findings indicate that supplier integration is important to performance, but in a different way than internal and customer integration are. While customer integration was significantly related to operational performance both directly and through its interaction with supplier integration, supplier integration was only significant as part of the interaction term. Since the objective of SCI is to provide maximum value to the customer, the measurement of operational performance is necessarily customer-oriented. Supplier integration may not contribute to operational performance directly, but instead interacts with customer integration in improving operational performance, reflecting the importance of manufacturers' integration with both downstream and upstream supply chain partners. Our study also indicates that, while internal integration was positively related to business performance, supplier and customer integration were not directly related to business performance. This may be because customer and supplier integration are related to business performance through operational performance.

Overall, the contingency approach reveals that internal integration forms the foundation upon which customer and supplier integration build. This suggests that companies should begin SCI with internal integration, laying the foundation for customer and supplier integration. This is a particularly important finding, since much of the prior research has failed to include internal integration, instead focusing only on customer and/or supplier integration. This suggests that the best approach to $\mathrm{SCI}$ is to start by developing internal integration capabilities and then to build external customer and supplier integration capabilities.

The configuration approach showed that the overall $\mathrm{SCI}$ construct was related to both operational and business performance. Because supply chain strength was more strongly related to performance than supply chain balance, the best performance was

Table 9

Analysis of variance.

\begin{tabular}{|c|c|c|c|c|c|c|}
\hline & $\begin{array}{l}\text { Medium customer } \\
\text { leaning (cluster } 1 \text { ) }\end{array}$ & $\begin{array}{l}\text { High customer } \\
\text { leaning (cluster 2) }\end{array}$ & $\begin{array}{l}\text { Low uniform } \\
\text { (cluster 3) }\end{array}$ & $\begin{array}{l}\text { Medium uniform } \\
\text { (cluster } 4 \text { ) }\end{array}$ & $\begin{array}{l}\text { High uniform } \\
\text { (cluster 5) }\end{array}$ & $F$ \\
\hline Operational performance & $5.18(2,5)$ & $5.79(1,3,4)$ & $4.96(2,5)$ & $5.12(2,5)$ & $6.12(1,3,4)$ & $38.67^{* * *}$ \\
\hline Business performance & $3.99(3,5)$ & $4.30(3,4)$ & $3.42(1,2,5)$ & $3.73(2,5)$ & $4.50(1,3,4)$ & $18.20^{* * *}$ \\
\hline
\end{tabular}

Numbers in parentheses indicate the cluster(s) from which that cluster is significantly different at $p<0.05 .{ }^{*} p<0.05 .{ }^{* *} p<0.01$.

**** $p<0.001$. 
achieved by manufacturers which were strong across the board in internal, customer and supplier integration. However, because the High Customer Leaning pattern was indistinguishable from the High Uniform Pattern, in terms of its relationship to performance, this means that both patterns have a similar effect. Thus, if a manufacturer has limited resources or is early in its SCI efforts, it can start by establishing a foundation of internal integration, then follow on by developing strong customer integration. The finding that the emergent SCI patterns are related to different levels of performance provides significant implications for companies to pursue the better performance through better SCI configuration (Das et al., 2006; Frohlich and Westbrook, 2001).

It is interesting to compare the results of our taxonomy, which included internal integration as a taxon, with Frohlich and Westbrook's (2001) taxonomy, which did not include internal integration. Our High Uniform pattern is similar to their OutwardFacing pattern, which included the upper quartile of both customer and supplier integration, and our High Customer Leaning pattern is similar to Frohlich and Westbrook's (2001) Customer-Facing pattern. Our Medium Uniform pattern is similar to their Periphery-Facing pattern, which includes the medium quartiles of customer and supplier integration, and our Low Uniform pattern is similar to their Inward-Facing pattern. Only our Medium Customer Leaning pattern did not correspond to any pattern in Frohlich and Westbrook's (2001) taxonomy. Similarly, we found that a pattern corresponding to Frohlich and Westbrook's (2001) Supplier-Facing pattern did not emerge in our taxonomy. However, our findings about the relationship between SCI patterns and performance generally support those of Frohlich and Westbrook (2001).

The configuration approach also reveals that the effect of $\mathrm{SCI}$ is cumulative, providing significant insight for companies in implementing it. Improvements in SCI will not lead to improved operational performance, when the level of SCI is relatively low (from Low Uniform to Medium Customer Leaning or Medium Uniform). However, once a threshold level of SCI has been achieved, further improvements in SCI, even small improvements, will be associated with significantly improved operational performance.

The findings from the contingency approach and those from the configuration approach are complementary. On one hand, the contingency approach found that internal and customer integration are the differentiators of performance and that supplier integration is not directly related to performance. The nonsignificant difference between the performance of the High Uniform pattern and that of the High Customer Leaning pattern in the configuration approach echoes this contingent finding. On the other hand, the contingency approach found that each dimension of SCI and the interactions between them are related to performance, which was overlooked by the configuration approach. However, the configuration approach found that companies' SCI pattern is related to performance and SCI capability is cumulative in improving performance, which was not revealed by the contingency approach. Thus, it is important that research on SCI continue to apply both a contingency and a configuration approach to tease out all important relationships.

\section{Conclusions and limitations}

This study extends the existing research on SCI in several important ways. First, it adds to the literature by empirically testing the relationship between $\mathrm{SCI}$ and performance. In including both internal and external integration and their interactions, and incorporating both operational and business performance, this study adds greater comprehensiveness and richness to the SCI literature and enhances our understanding of the impact of $\mathrm{SCI}$ on performance.
Second, this research describes SCI in three dimensions: internal, customer and supplier integration, finding that internal integration forms the foundation upon which customer and supplier integration build. It further develops a taxonomy of SCI based on internal, customer and supplier integration. Although Frohlich and Westbrook's (2001) taxonomy identified five SCI patterns based on customer and supplier integration, internal integration was not included in their dimensions. Similarly, Devaraj et al. (2007) considered only supplier and customer integration, but did not include internal integration. Droge et al. (2004) considered internal and external integration, but did not break down external integration into customer and supplier integration, as we did. Our findings provide preliminary evidence of the importance of including internal integration in developing SCI patterns, as well as establishing a direct relationship between internal integration and performance. Internal integration provides a vital link between customer integration and supplier integration, without which companies are unable to reap the full benefits of their SCI efforts.

Our findings extend the SCI literature by indicating the importance of SCI practices across industries in China. Previous related research has focused on other contexts, for example, the North American automotive industry (Droge et al., 2004; Devaraj et al., 2007). China has become a global manufacturing center and an attractive target for outsourcing by Western firms. Effective SCI can help make Chinese companies even more attractive supply chain partners through reduction of transaction costs. Chinese manufacturers can improve their business performance through enhancing integration of their own internal processes and with their customers and suppliers.

While our study makes a significant contribution to the SCI literature and has important implications for practice, there are some limitations and opportunities for future studies. First, this study uses a cross-sectional design. Because integration between customers, suppliers and manufacturers is developed over time, it will be fruitful for future research to examine the evolution of SCI patterns in a longitudinal fashion. Second, because the data were only collected from manufacturers, future studies can broaden their scope by collecting data from all supply chain partners, including suppliers, manufacturers and customers. Third, although this research provided some interesting findings about the relationship between SCI and performance in China, it is not clear whether these relationships will be the same in other countries. Future research should examine cross-cultural differences in the relationship between $\mathrm{SCI}$ and performance. In particular, studies which compare $\mathrm{SCI}$ in developed versus developing economies will be of interest. Finally, by focusing on various industries, company sizes and regions, we developed a broad picture of the relationship between SCI pattern and performance. However, these relationships may not be the same for all company sizes, industries or regions. Future research should examine the impact of these contextual factors on SCI patterns and their relationship with performance.

Another interesting area of research is the factors that influence the degree of customer, supplier and internal integration in the SCI patterns. These factors may include factors such as the competitive environment, relationship commitment, trust, organizational characteristics and national culture. Likewise, the relationship between SCI and competitive performance is another potentially interesting area for future study. For example, Bowersox et al.'s (1999) work on the importance of SCI as a differentiator of overall performance, compared with other differentiating factors, could be extended to incorporate our taxonomy of SCI. In a similar vein, this taxonomy could be used to build on Swink et al.'s (2007) work to 
determine whether different patterns of SCI have differing impacts on competitive capabilities and performance.

SCI is an increasingly important area of research, as supply chains become more widely dispersed across the globe. This research addresses some fundamental issues in $\mathrm{SCI}$, as well as raising a number of critical research questions that remain to be resolved.

\section{Acknowledgement}

The authors would like to acknowledge the financial support provided by the Research Grants Council (RGC) of Hong Kong and the Center for Supply Chain Management \& Logistics, Li \& Fung Institute of Supply Chain Management \& Logistics, The Chinese University of Hong Kong.

\section{Appendix A. Summary of prior literature on the relationship between SCI and performance}

\begin{tabular}{|c|c|c|}
\hline Study & Dimensions of supply chain integration & Performance \\
\hline Armistead and Mapes (1993) & $\mathrm{SCI}$ & Operational performance \\
\hline Cousins and Menguc (2006) & Supplier integration & $\begin{array}{l}\text { Supplier's operational/communication performance } \\
\text { Supplier's contractual conformance }\end{array}$ \\
\hline Das et al. (2006) & Supplier integration & Operational performance \\
\hline Devaraj et al. (2007) & $\begin{array}{l}\text { Supplier integration } \\
\text { Customer integration }\end{array}$ & Operational performance \\
\hline Droge et al. (2004) & $\begin{array}{l}\text { Strategic design integration } \\
\text { Design-process integration } \\
\text { Supplier integration } \\
\text { Customer integration }\end{array}$ & $\begin{array}{l}\text { Time to market } \\
\text { Product responsiveness } \\
\text { Firm performance }\end{array}$ \\
\hline Frohlich and Westbrook (2001) & $\begin{array}{l}\text { Supplier integration } \\
\text { Customer integration }\end{array}$ & $\begin{array}{l}\text { Marketplace performance } \\
\text { Productivity performance Non-productivity performance }\end{array}$ \\
\hline Germain and Iyer (2006) & $\begin{array}{l}\text { Internal integration } \\
\text { Downstream integration }\end{array}$ & $\begin{array}{l}\text { Logistics performance } \\
\text { Financial performance }\end{array}$ \\
\hline Gimenez and Ventura (2005) & $\begin{array}{l}\text { Logistics-production integration } \\
\text { Logistics-marketing integration } \\
\text { External integration }\end{array}$ & $\begin{array}{l}\text { Cost reduction } \\
\text { Stock-out reduction } \\
\text { Lead time reduction }\end{array}$ \\
\hline $\begin{array}{l}\text { Homburg and Stock (2004) } \\
\text { Johnson (1999) }\end{array}$ & $\begin{array}{l}\text { Customer integration } \\
\text { Strategic integration }\end{array}$ & $\begin{array}{l}\text { Customer satisfaction } \\
\text { Financial performance }\end{array}$ \\
\hline Koufteros et al. (2007) & Supplier integration & $\begin{array}{l}\text { Product innovation } \\
\text { External quality }\end{array}$ \\
\hline Koufteros et al. (2005) & $\begin{array}{l}\text { Internal integration } \\
\text { Customer integration } \\
\text { Supplier product integration } \\
\text { Supplier process integration }\end{array}$ & $\begin{array}{l}\text { Product innovation } \\
\text { Quality } \\
\text { Profitability }\end{array}$ \\
\hline Marquez et al. (2004) & $\mathrm{SCI}$ & Operational and financial effectiveness \\
\hline Morash and Clinton (1998) & $\begin{array}{l}\text { Intra-organizational process integration } \\
\text { Inter-organizational collaborative/operational integration }\end{array}$ & $\begin{array}{l}\text { Total cost reduction strategy } \\
\text { Differentiation strategy }\end{array}$ \\
\hline Narasimhan and Kim (2002) & $\begin{array}{l}\text { Internal integration } \\
\text { Supplier integration } \\
\text { Customer integration }\end{array}$ & $\begin{array}{l}\text { Moderator of the relationship between international } \\
\text { market/product diversification and firm performance }\end{array}$ \\
\hline Pagell (2004) & Internal integration & Performance \\
\hline Petersen et al. (2005) & Supplier integration & $\begin{array}{l}\text { Project team effectiveness } \\
\text { Firm financial performance } \\
\text { Design performance }\end{array}$ \\
\hline Ragatz et al. (2002) & Supplier integration & Cycle time results \\
\hline Rosenzweig et al. (2003) & $\mathrm{SCI}$ & $\begin{array}{l}\text { Competitive capabilities } \\
\text { Business performance }\end{array}$ \\
\hline Saeed et al. (2005) & $\begin{array}{l}\text { Internal integration } \\
\text { External integration }\end{array}$ & $\begin{array}{l}\text { Process efficiency } \\
\text { Sourcing leverage }\end{array}$ \\
\hline Stank et al. (2001a) & $\begin{array}{l}\text { Customer integration } \\
\text { Internal integration } \\
\text { Supplier integration, } \\
\text { Technology and planning } \\
\text { Measurement integration } \\
\text { Relationship integration }\end{array}$ & Overall logistics performance \\
\hline Stank et al. (2001b) & $\begin{array}{l}\text { Internal collaboration } \\
\text { External collaboration }\end{array}$ & Logistics service performance \\
\hline Swink et al. (2007) & $\begin{array}{l}\text { Strategic supplier integration } \\
\text { Strategic customer integration }\end{array}$ & $\begin{array}{l}\text { Manufacturing competitive capabilities } \\
\text { Business performance }\end{array}$ \\
\hline
\end{tabular}




\begin{tabular}{|c|c|c|}
\hline$\overline{\text { Study }}$ & Dimensions of supply chain integration & Performance \\
\hline & $\begin{array}{l}\text { Product-process technology integration } \\
\text { Corporate strategy integration }\end{array}$ & \\
\hline Vickery et al. (2003) & SCI & $\begin{array}{l}\text { Customer service } \\
\text { Financial performance }\end{array}$ \\
\hline
\end{tabular}

\section{Appendix B. Measurement items (with factor loadings)}

Customer integration (eigenvalue $=5.38$ ). Please indicate the extent of integration or information sharing between your organization and your major customer in the following areas ( $1=$ not at all; 7 =extensive).

The level of linkage with our major customer through information networks.

The level of computerization for our major customer's ordering.

The level of sharing of market information from our major customer.

The level of communication with our major customer.

The establishment of quick ordering systems with our major customer.

Follow-up with our major customer for feedback.

The frequency of period contacts with our major customer.

Our major customer shares Point of Sales (POS) information with us.

Our major customer shares demand forecast with us.

We share our available inventory with our major customer.

We share our production plan with our major customer.

Supplier integration (eigenvalue $=7.91$ ). Please indicate the extent of integration or information sharing between your organization and your major supplier in the following areas $(1=$ not at all; $7=$ extensive $)$.

The level of information exchange with our major supplier through information networks.

The establishment of quick ordering systems with our major supplier.

The level of strategic partnership with our major supplier.

Stable procurement through network with our major supplier.

The participation level of our major supplier in the process of procurement and production.

The participation level of our major supplier in the design stage.

Our major supplier shares their production schedule with us.

Our major supplier shares their production capacity with us.

Our major supplier shares available inventory with us.

We share our production plans with our major supplier.

We share our demand forecasts with our major supplier.

We share our inventory levels with our major supplier.

We help our major supplier to improve its process to better meet our needs.

Internal integration (eigenvalue $=6.19)$. Please indicate the degree of integration in the following areas $(1=n o t$ at all; $7=$ extensive) .

Data integration among internal functions.

Enterprise application integration among internal functions.

Real-time searching of the level of inventory.

Real-time searching of logistics-related operating data.

The utilization of periodic interdepartmental meetings among internal functions.

The use of cross functional teams in process improvement.

The use of cross functional teams in new product development.

Real-time integration and connection among all internal functions from raw material management through production, shipping, and sales.

Operational performance (eigenvalue $=3.616$ ). Please indicate the degree to which you agree to the following statements concerning your company's performance with respect to your major customer ( $1=$ strongly disagree; $7=$ strongly agree).

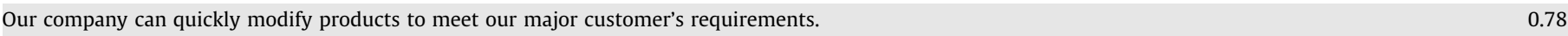

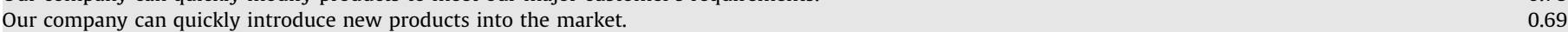

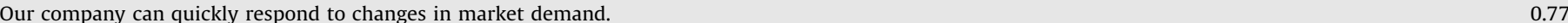

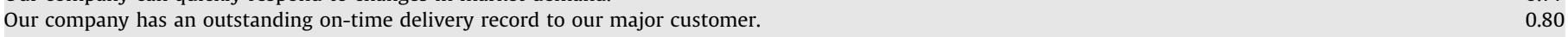

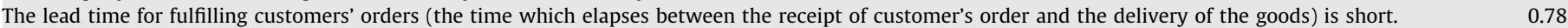

Our company provides a high level of customer service to our major customer.

Business performance (eigenvalue $=5.111$ ). Please evaluate your company's performance in the following areas relative to your primary/ major competitors ( 1 = much worse; 7 = much better). 


\section{References}

Anderson, J.C., Gerbing, D.W., 1988. Structural equation modeling in practice: a review and recommended two-step approach. Psychological Bulletin 103 (2), 411-423.

Armistead, C.G., Mapes, J., 1993. The impact of supply chain integration on operating performance. Logistics Information Management 6 (4), 9-14.

Armstrong, J.S., Overton, T.S., 1977. Estimating nonresponse bias in mail surveys. Journal of Marketing Research 14 (3), 396-402.

Bagozzi, R.P., Yi, Y., Phillips, L.W., 1991. Assessing construct validity in organizational research. Administrative Science Quarterly 36 (3), 421-458.

Beamon, B.M., 1999. Measuring supply chain performance. International Journal of Operations \& Production Management 19 (3), 275-292.

Bowersox, D.J., Closs, D.J., Stank, T.P., 1999. 21st Century Logistics: Making Supply Chan Integration a Reality. Michigan State University, Council of Logistics Management.

Bowersox, D.J., Morash, E.A., 1989. The integration of marketing flows in channels of distribution. European Journal of Marketing 23 (20), 58-67.

Campbell, J., Sankaranl, J., 2005. An inductive framework for enhancing supply chain integration. International Journal of Production Research 43 (16), 3321-3351.

Cespedes, F., 1996. Beyond teamwork: how the wise can synchronize. Marketing Management 5 (1), 25-37.

Chandler Jr., A.D., 1962. Strategy and Structure. MIT Press, Cambridge, MA.

Chen, I.J., Paulraj, A., 2004a. Understanding supply chain management: critical research and a theoretical framework. International Journal of Production Research 42 (1), 131-163.

Chen, I.J., Paulraj, A., 2004b. Towards a theory of supply chain management: the constructs and measurements. Journal of Operations Management 22 (2), 119150.

Cousins, P.D., Menguc, B., 2006. The implications of socialization and integration in supply chain management. Journal of Operations Management 24 (5), 604-620.

Das, A., Narasimhan, R., Talluri, S., 2006. Supplier integration-finding an optimal configuration. Journal of Operations Management 24 (5), 563-582.

Devaraj, S., Krajewski, L., Wei, J.C., 2007. Impact of e-business technologies on operational performance: the role of production information in the supply chain. Journal of Operations Management 25 (6), 1199-1216.

Dixon, J.R., Nanni, A.J., Vollmann, T.E., 1990. The New Performance ChallengeMeasuring Operations for World-Class Competition. Dow Jones-Irwin, Homewood, IL.

Donaldson, L., 2001. The Contingency Theory of Organizations. Sage, Thousand Oaks, CA.

Drazin, Robert, Van de Ven, Andrew, H., 1985. Alternative forms of fit in contingency theory. Administrative Science Quarterly 30 (4), 514-539.

Droge, C., Jayaram, J., Vickery, S.K., 2004. The effects of internal versus external integration practices on time-based performance and overall firm performance. Journal of Operations Management 22 (6), 557-573.

Eccles, R.G., Pyburn, P.J., 1992. Creating a comprehensive system to measure performance. Management Accounting 74 (4), 41-44.

Ellram, L., 1990. The supplier selection decision in strategic partnerships. Journal of Purchasing and Materials Management 26 (4), 8-14.

Fawcett, S.E., Magnan, G.M., 2002. The rhetoric and reality of supply chain integration. International Journal of Physical Distribution and Logistics Management 32 (5), 339-361.

Fornell, C., Larcker, D.F., 1981. Evaluating structural equation models with unobservable variables and measurement error. Journal of Marketing Research 18 (1), 29-50.

Frohlich, M.T., 2002. Techniques for improving response rates in OM survey research. Journal of Operations Management 20 (1), 53-62.

Frohlich, M.T., Westbrook, R., 2001. Arcs of integration: an international study of supply chain strategies. Journal of Operations Management 19 (2), 185-200.

Galbraith, J.R., 1973. Designing Complex Organizations. Addison-Wesley.

Germain, R., Iyer, K.N.S., 2006. The interaction of internal and downstream integration and its association with performance. Journal of Business Logistics 27 (2), 29-53.

Gimenez, C., Ventura, E., 2005. Logistics-production, logistics-marketing and external integration: their impact on performance. International Journal of Operations \& Production Management 25 (1), 20-38.

Hair, J.F., Anderson, R.E., Tatham, R.L., Black, W.C., 1998. Multivariate Data Analysis. Prentice Hall, New Jersey.

Hall, R.W., 1983. Zero Inventories. Dow-Jones Irwin, Homewood.

Hambrick, D.C., 1983. High profit strategies in mature capital goods industries: a contingency approach. Academy of Management Journal 26 (4), 687-707.

Hammer, M., 1990. Reengineering work: don't automate, obliterate. Harvard Business Review 68 (4), 104-112.

Harland, C.M., Caldwell, N.D., Powell, P., Zheng, J., 2007. Barriers to supply chain information integration: SMEs adrift of eLands. Journal of Operations Management 25 (6), 1234-1254

Heide, J., John, J., 1990. Alliances in industrial purchasing: the determinants of joint action in buyer-supplier relationships. Journal of Marketing Research 27 (1), 24-36.

Hillebrand, B., Biemans, W.G., 2003. The relationship between internal and external cooperation: literature review and propositions. Journal of Business Research 56 (9), 735-743.

Hochwarter, W.A., James, M., Johnson, D., Ferris, F.R., 2004. The interactive effects of politics perceptions and trait cynicism on work outcomes. Journal of Leadership \& Organizational Studies 10 (4), 44-57.
Homburg, C., Stock, R.M., 2004. The link between salespeople's job satisfaction and customer satisfaction in a business-to-business context: a dyadic analysis. Journal of Academy of Marketing Science 32 (2), 144-158.

$\mathrm{Hu}$, L., Bentler, P.M., 1999. Cutoff criteria for fit indices in covariance structure analysis: conventional criteria versus new alternatives. Structural Equation Modeling 6 (1), 1-55.

Johnson, H.T., Kaplan, R.S., 1987. Relevance lost-the rise and fall of management accounting. Canadian Business Review 14 (4), 48-50.

Johnson, J.L., 1999. Strategic integration in industrial distribution channels: managing the interfirm relationship as a strategic asset. Journal of Academy of Marketing Sciences 27 (1), 4-18.

Kahn, K.B., Mentzer, J.T., 1996. Logistics and interdepartmental integration. International Journal of Physical Distribution and Logistics Management 26 (8), 614.

Kingman-Brundage, J., George, W., Bowen, D., 1995. Service logic: achieving service system integration. International Journal of Service Industry Management 6 (4) 20-39.

Kotha, S., Nair, A., 1995. Strategy and environment as determinants of performance: evidence from the Japanese machine tool industry. Strategic Management Journal 16 (7), 497-518.

Koufteros, X., Vonderembse, M., Jayaram, J., 2005. Internal and external integration for product development: the contingency effects of uncertainty, equivocality, and platform strategy. Decision Sciences 36 (1), 97-133.

Koufteros, X.A., Cheng, T.C.E., Lai, K.H., 2007. Black-box and gray box supplier integration in product development: antecedents, consequences and the moderating role of firm size. Journal of Operations Management 25 (4), 847-870.

Lambert, D.M., Cooper, M.C., 2000. Issues in supply chain management. Industrial Marketing Management 29 (1), 65-83.

Lambert, D.M., Robeson, J.F., Stock, J.R., 1978. An appraisal of the integrated physical distribution management concept. International Journal of Physical Distribution and Materials Management 9 (1), 74-88.

Lawrence, P.R., Lorsch, J.W., 1967. Organization and Environment. Harvard University Press, Cambridge MA.

Lee, H.L., Whang, S., 2001. Winning the last mile of e-commerce. Sloan Management Review 42 (4), 54-62.

Mabert, V.A., Venkataramanan, M.A., 1998. Special research focus on supply chain linkages: challenges for design and management in the 21 st century. Decision Sciences 29 (1), 537-552.

Marquez, A.C., Bianchi, C., Gupta, J.N.D., 2004. Operational and financial effectiveness of e-collaboration tools in supply chain integration. European Journal of Operational Research 159 (2), 348-363.

Milgrom, P., Roberts, J., 1995. Complementarities and fit: strategy, structure and organizational change in manufacturing. Journal of Accounting and Economics $19(2 / 3), 179-208$

Miller, D., 1986. Configuration of strategy and structure: towards a synthesis. Strategic Management Journal 7 (3), 233-249.

Miller, J.G., Roth, A.V., 1994. A taxonomy of manufacturing strategies. Management Science 40 (3), 285-304.

Morash, E.A., Clinton, S.R., 1998. Supply chain integration: customer value through collaborative closeness versus operational excellence. Journal of Marketing Theory and Practice 6 (4), 104-120.

Narasimhan, R., Kim, S.W., 2002. Effect of supply chain integration on the relationship between diversification and performance: evidence from Japanese and Korean firms. Journal of Operations Management 20 (3), 303-323.

Naylor, J.B., Naim, M.M., Berry, D., 1999. Leagility: integrating the lean and agile manufacturing paradigms in the total supply chain. International Journal of Production Economics 62 (1/2), 107-118.

Neely, A., Gregory, M., Platts, K., 1995. Performance measurement system design. International Journal of Operations \& Production Management 15 (4), 80116.

O'Leary-Kelly, S.W., Flores, B.E., 2002. The integration of manufacturing and marketing/sales decisions: impact on organizational performance. Journal of Operations Management 20 (3), 221.

O'Leary-Kelly, S.W., Vokurka, R.J., 1998. The empirical assessment of construct validity. Journal of Operations Management 16 (4), 387-405.

Pagell, M., 2004. Understanding the factors that enable and inhibit the integration of operations, purchasing and logistics. Journal of Operations Management 22 (5), 459-487.

Paulraj, A., Lado, A., Chen, J., 2008. Inter-organizational communication as a relational competency: antecedents and performance outcomes in collaborative buyer-supplier relationships. Journal of Operations Management 26 (1), 45-64.

Petersen, K., Handfield, R., Ragatz, G., 2005. Supplier integration into new product development: coordinating product, process, and supply chain design. Journal of Operations Management 23 (3/4), 371-388.

Podsakoff, P.M., MacKenzie, S.B., Lee, J.Y., Podsakoff, N.P., 2003. Common method bias in behavioral research: a critical review of the literature and recommended remedies. Journal of. Applied Psychology 88 (5), 879-903.

Podsakoff, P.M., Organ, D.W., 1986. Self-reports of organizational research: problems and prospects. Journal of Management 12 (4), 531-544.

Poirier, C.C., Reiter, S.E., 1996. Supply Chain Optimization: Building the Strongest Total Business Network. Berrett-Koehler Publishers.

Ragatz, G.L., Handfield, R.B., Petersen, K.J., 2002. Benefits associated with supplier integration into new product development under conditions of technology uncertainty. Journal of Business Research 55 (5), 389-400.

Rosenzweig, E.D., Roth, A.V., Dean Jr., J.W., 2003. The influence of an integration strategy on competitive capabilities and business performance: an exploratory 
study of consumer products manufacturers. Journal of Operations Management 21 (4), 437-456.

Saeed, K.A., Malhotra, M.K., Grover, V., 2005. Examining the impact of interorganizational systems on process efficiency and sourcing leverage in buyer-supplier dyads. Decision Sciences 36 (3), 365-396.

Sanchez, J.I., Brock, P., 1996. Outcomes of perceived discrimination among hispanic employees: is diversity management a luxury or a necessity? Academy of Management Journal 39 (3), 704-719.

Sanders, N.R., 2008. Pattern of information technology use: the impact on buyersuppler coordination and performance. Journal of Operations Management 26 (3), 349-367.

Scott, W.R., Cole, R., 2000. Introduction. In: Cole, R., Scott, W.R. (Eds.), The Quality Movement and Organizational Theory. Sage, Thousand Oaks.

Siggelkow, Nicholaj, 2001. Change in the presence of fit: the rise, the fall and the renaissance of Liz Claiborne. Academy of Management Journal 44 (4), 838-857.

Sinha, Kingshuk, K., Van de Ven, Andrew, H., 2005. Designing work within and between organizations. Organization Science 16 (4), 389-408.

Skinner, W., 1971. The anachronistic factory. Harvard Business Review 49 (1), 61 70.

Song, M., Di Benedetto, C.A., 2008. Supplier's involvement and success of radical new product development in new ventures. Journal of Operations Management 26 (1), 1-22.

Spekman, R.E., Kamauff Jr., J.W., Myrh, N., 1998. An empirical investigation into supply chain management: a perspective on partnerships. International Journal of Physical Distribution and Logistics Management 28 (8), 630-650.

Stank, T.P., Keller, S.B., Closs, D.J., 2001a. Performance benefits of supply chain integration. Transportation Journal 41 (2), 31-46.

Stank, T.P., Keller, S.B., Daugherty, P.J., 2001b. Supply chain collaboration and logistical service performance. Journal of Business Logistics 22 (1), 29-48.

Stanley, L.L., Wisner, J.D., 2001. Service quality along the supply chain: implications for purchasing. Journal of Operations Management 19 (3), 287-306.

Stevens, G.C., 1989. Integrating the supply chain. International Journal of Physical Distribution and Logistics Management 19 (8), 3-8.

Swink, M., Narasimhan, R., Wang, C., 2007. Managing beyond the factory walls: effects of four types of strategic integration on manufacturing plant performance. Journal of Operations Management 25 (1), 148-164.

Thompson, J.D., 1967. Organizations in Action. McGraw-Hill, New York, NY.

Tushman, M.L., Nadler, D.A., 1978. Information processing as an integrating concept in organization design. Academy of Management Review 3 (3), 613-624.

Van der Vaart, T., van Donk, D., 2008. A critical review on survey-based research in supply chain integration. International Journal of Production Economics 111 (1), 42-55.

Van Hoek, R.I., 1998. Measuring the unmeasurable-measuring and improving performance in the supply chain. Journal of Supply Chain Management 3 (4) 187-192.

Venkatraman, N., Prescott, J., 1990. Environment-strategy coalignment: an empirical test of its performance implications. Strategic Management Journal 11 (1), $1-23$.

Vickery, S.K., Jayaram, J., Droge, C., Calantone, R., 2003. The effects of an integrative supply chain strategy on customer service and financial performance: an analysis of direct versus indirect relationships. Journal of Operations Management 21 (5), 523-539.

Ward, P.T., Bickford, D.J., Leong, G.K., 1996. Configurations of manufacturing strategy, business strategy, environment, and structure. Journal of Management 22 (4), 597-626.

Webster's Third New International Dictionary, 1966. William Benton, Chicago.
Widaman, K., 1985. Hierarchically nested covariance structure models for multitrait-multimethod data. Applied Psychological Measurement 9 (1), 1-26.

Williams, L.J., Cote, J.A., Buckley, M.R., 1989. Lack of method variance in selfreported affect and perceptions at work: reality or artifact. Journal of Applied Psychology 74 (3), 462-468.

Wisner, J.D., Tan, K.C., 2000. Supply chain management and its impact on purchasing. Journal of Supply Chain Management 36 (4), 33-42.

Zailani, S., Rajagopal, P., 2005. Supply chain integration and performance: US versus East Asian companies. Supply Chain Management 10 (5), 379-393.

Zhao, X., Flynn, B.B., Roth, A.V., 2006a. Decision sciences research in China: a critical review and research agenda-foundations and overview. Decision Sciences 37 (4), 451-496.

Zhao, X., Huo, B., Flynn, B.B., Yeung, J., 2008. The impact of power and relationship commitment on the integration between manufacturers and customers in a supply chain. Journal of Operations Management 26 (3), 368-388.

Zhao, X., Sum, C.-C., Oi, Y., Zhang, H., Lee, T., 2006b. A taxonomy of manufacturing strategies in China. Journal of Operations Management 24 (5), 621-636.

Dr. Barbara Flynn is the Richard M. and Myra Louise Buskirk professor of manufacturing management and director of the Center for International Business Education and Research (IU CIBER) at the Kelley School of Business at Indiana University. She received a DBA in operations management from Indiana University and an MBA from Marquette University. She is a fellow of the Decision Sciences Institute and recipient of the Distinguished Scholar Award from the Operations Management division of the Academy of Management and the Dennis E. Grawoig Distinguished Service Award from the Decision Sciences Institute. Dr. Flynn has received over $\$ 1$ million in research funding from the National Science Foundation, the U.S. Department of Education and the Center for Innovation Management Studies. She has published articles in Management Science, Decision Sciences, Journal of Operations Management, International Journal of Operations and Production Management and other leading journals, as well as a book and numerous book chapters. Dr. Flynn is founding editor of Decision Sciences Journal of Innovative Education and past Editor of Quality Management Journal. She is a past President of the Decision Sciences Institute and has held leadership positions in the Decision Sciences Institute, Academy of Management and American Society for Quality.

Dr. Baofeng Huo is an assistant professor of operations management at the School of Management at Xi'an Jiaotong University and research fellow at Center for Supply Chain Management \& Logistics, Li \& Fung Institute of Supply Chain Management \& Logistics, The Chinese University of Hong Kong. He received his $\mathrm{PhD}$ in operations management from The Chinese University of Hong Kong. His research interests are logistics and supply chain management. His research has been published in the Journal of Operations Management, International Journal of Operations and Production Management, International Journal of Production Economics, Business Horizon, and other journals.

Dr. Xiande Zhao is professor of operations management at the Department of Decision Sciences and Managerial Economics and director of the Center for Supply Chain Management and Logistics, Li \& Fung Institute of Supply Chain Management and Logistics, The Chinese University of Hong Kong. He received his PhD in business administration and MBA from the University of Utah. U.S.A. Prof. Zhao's teaching and research interests are in the areas of supply chain management and service operations management. He has published over fifty articles in refereed journals including the Journal of Operations Management, Journal of Consumer Research, Decision Sciences, European Journal of Operations Research, International Journal of Production Research and other journals. 